\title{
Influenza Infections and Emergent Viral Infections in Intensive Care Unit
}

\author{
Ben Cantan, BMBS ${ }^{1}$ Charles-Edouard Luyt, MD, $\mathrm{PhD}^{2,3}$ Ignacio Martin-Loeches, MD ${ }^{1,4,5}$ \\ ${ }^{1}$ Multidisciplinary Intensive Care Research Organization, \\ St James's Hospital, Dublin, Ireland \\ 2 Médecine Intensive Réanimation, Hôpital Pitié-Salpêtrière, \\ Assistance Publique-Hôpitaux de Paris, Sorbonne University \\ (Paris 6), Paris, France \\ 3 INSERM, UMRS 1166-iCAN, Institute of Cardiometabolism and \\ Nutrition, Paris, France \\ ${ }^{4}$ Department of Pulmonology, Hospital Clínic de Barcelona, \\ Universitat de Barcelona and IDIBAPS, Barcelona, Spain \\ ${ }^{5}$ Centro de Investigación Biomédica en Red (CIBER), University of \\ Barcelona, Barcelona, Spain \\ Semin Respir Crit Care Med 2019;40:488-497. \\ Address for correspondence Ignacio Martin-Loeches, MD, \\ Multidisciplinary Intensive Care Research Organization, St James's \\ Hospital, St James Street, Dublin 8, Ireland \\ (e-mail: drmartinloeches@gmail.com).
}

Abstract

\section{Keywords}

- community-acquired respiratory infections

- herpesviridae

- intensive care unit
Critically ill patients are admitted to an intensive care unit (ICU) for multiple reasons. In this study, we aim to analyze the current evidence and findings associated with influenza and other emergent viral infections, namely, herpes simplex virus type 1 (HSV-1), Epstein-Barr virus (EBV), and cytomegalovirus (CMV).

Among medical conditions, community-acquired respiratory infections are the most frequent reason for ventilatory support in ICUs. Community-acquired pneumonia in a severe form including the need of invasive mechanical ventilation and/or vasopressors is associated with high mortality rates. However, after the pandemic that occurred in 2009 by H1N1 influenza, the number of cases being admitted to ICUs with viral infections is on the rise. Patients in whom an etiology would not have been identified in the past are currently being tested with more sensitive viral molecular diagnostic tools, and patients being admitted to ICUs have more preexisting medical conditions that can predispose to viral infections. Viral infections can trigger the dysregulation of the immune system by inducing a massive cytokine response. This cytokine storm can cause endothelial damage and dysfunction, deregulation of coagulation, and, consequently, alteration of microvascular permeability, tissue edema, and shock. In severe influenza, this vascular hyperpermeability can lead to acute lung injury, multiorgan failure, and encephalopathy. In immunocompetent patients, the most common viral infections are respiratory, and influenza should be considered in patients with severe respiratory failure being admitted to ICU. Seasonality and coinfection are two important features when considering influenza as a pathogen in critically ill patients. Herpesviridae (HSV, CMV, and EBV) may reactivate in ICU patients, and their reactivation is associated with morbidity/mortality. However, whether a specific treatment may impact on outcome remains to be determined.
Issue Theme Serious Infections in the ICU: Evolving Concepts in Management and Prevention; Guest Editors: Jean Chastre, MD, Charles-Edouard Luyt, MD, $\mathrm{PhD}$, and Michel Wolff, MD
Copyright $\odot 2019$ by Thieme Medical Publishers, Inc., 333 Seventh Avenue, New York, NY 10001, USA.

Tel: +1(212) 584-4662.
DOI https://doi.org/ 10.1055/s-0039-1693497. ISSN 1069-3424. 
Critically ill patients are admitted to an intensive care unit (ICU) due to multiple reasons. Among medical conditions, community-acquired respiratory infections are the most frequent reason for ventilatory support in ICUs. Community-acquired pneumonia (CAP) in a severe form including the need of invasive mechanical ventilation and/or vasopressors is associated with high mortality rates. The most common etiology is bacterial, with Streptococcus pneumoniae causing almost half of the episodes of CAP when the etiology is identified. However, after the pandemic that occurred in 2009 by H1N1 influenza, the number of cases being admitted to ICUs with viral infections is on the rise. Patients in whom an etiology would not have been identified in the past are being tested with more sensitive viral molecular diagnostic tools; in addition, patients currently being admitted to ICU have more preexisting medical conditions that can predispose to viral infections.

In this study, we aimed to analyze the current evidence and findings associated not only with influenza but also with other emergent and often opportunistic viral infections, namely herpes simplex virus type 1 (HSV-1), Epstein-Barr virus (EBV), and cytomegalovirus (CMV).

\section{Influenza}

\section{Introduction}

Influenza viruses belong to the Orthomyxovirus family. They are classified into influenza $A, B$, and $C$ based on their core proteins. The envelope of the influenza $A$ virus contains two major surface glycoproteins: hemagglutinin (HA) and neuraminidase (NA). HA is responsible for cell attachment and membrane fusion, and NA enables the release of new virions from the cell through its cleaving of the bonds between HA and sialic acid. It also has a role in viral ingress by cleaving sialylated mucins to allow virus penetration through the mucous layer. ${ }^{1}$

Influenza A viruses are subclassified based on the HA and NA glycoproteins. World Health Organization (WHO) nomenclature for the classification of influenza virus consists of the following two parts. ${ }^{2}$

\section{- Type and Strain Designation}

- For Influenza A Viruses: A Description of the Antigenic Specificity of the Surface Antigens ( $\mathrm{H}$ and $\mathrm{N}$ )

There are currently 18 subtypes of $\mathrm{HA}$ (H 1-18) and 11 subtypes of NA (N 1-11). These mostly circulate in wild birds. There are three combinations that are known to have circulated widely in humans: A/H1N1, A/H2N2, and A/H3N2. ${ }^{3}$ The influenza B virus was first isolated in 1940. It circulates solely in humans and has no animal reservoir. ${ }^{3}$

Minor changes in the protein structure of the influenza A virus are known as antigenic drift. These mutations allow the virus to evade the immune system and cause further outbreaks of influenza. Antigenic drifts occur in influenza A, B, and C viruses. The segmented genome of influenza $A$ virus genome allows for the exchange of entire gene segments in the event that two different influenza A viruses simultaneously infect and replicate in the same host cell. ${ }^{4}$ Antigenic shift is caused by reassortment of two different subtypes of influenza virus (such as between an animal and a human subtype), which causes a phenotypic change. Antigenic shift only occurs in influenza A virus as it infects more than just humans. Antigenic shifts can result in epidemics and pandemics. Both the pandemic strains in 1957 and 1968 were derived by genetic reassortment between human and avian viruses. ${ }^{5}$

\section{Epidemics and Pandemics}

Epidemics occur annually and, according to the WHO, result in an estimated 3 to 5 million cases of serious illness and in approximately 290,000 to 650,000 deaths per year. There were three influenza virus pandemics in the 20th century (1918, 1957, and 1968), and one pandemic in the 21st century (2009). ${ }^{6}$ The influenza pandemic of 1918 to 1919 was the most catastrophic in recorded history. An estimated one-third of the world's population ( $\sim 500$ million people) were infected with the virus. ${ }^{7}$ Total deaths were estimated at around 50 million, ${ }^{8,9}$; however, it is acknowledged that the death toll may have been significantly higher than this and may, in fact, have reached 100 million. $^{9}$

\section{Origin of Human Pandemic Strains}

Influenza viruses in humans originate from birds and swine. ${ }^{3}$ The first human influenza A virus was isolated in 1933 and was designated H1N1. This circulated until 1957 when it was replaced by the $\mathrm{H} 2 \mathrm{~N} 2$ subtype (Asian influenza). In 1968, the Hong Kong (H3N2) virus appeared, after which the H2N2 Asian strains were no longer detectable in humans. Then, in 1977, the H1N1 virus reappeared (likely having escaped from a laboratory)..$^{5}$ The $\mathrm{H} 1 \mathrm{~N} 1$ and $\mathrm{H} 3 \mathrm{~N} 2$ viruses, along with influenza B viruses, have continued to cocirculate in the human population, undergoing considerable evolution through antigenic drift. ${ }^{3}$

\section{Influenza: Pathophysiology}

Influenza virions recognize potential host cells by detecting sialic acid and binding to it using the HA viral glycoprotein. ${ }^{10}$ Sialic (N-acetylneuraminic) acid is found on nearly all animal cells. It forms either an $\alpha-2,3$ or $\alpha-2,6$ linkage, and it is this configuration that is recognized by the HA protein. ${ }^{10}$ The $\alpha-2,3$ linkage is the major sialic acid found in the gastrointestinal tract of the duck. In contrast, the major sialic acid found in upper respiratory epithelial cells in humans contains the $\alpha-2,6$ linkage. It is for this reason that not all avian strains can easily infect humans. For example, in order for avian influenza (H5N1) to infect humans, it must penetrate deep into the alveoli where there are more $\alpha-2,3$ receptors. ${ }^{11}$ Once the virus attaches to the host cell, it enters the cell through receptormediated endocytosis. The envelope fuses with the host cell, and M2 proteins (a target for amantadine) form ion channels, allowing entry of ribonucleoproteins necessary for viral uncoating and replication. ${ }^{10}$ Initial response to infection is characterized by proinflammatory state. Th1 cells are activated and release proinflammatory cytokines such as tumor necrosis factor- $\alpha$ (TNF- $\alpha)$, interferon- $\gamma($ IFN- $\gamma)$, and interleukin (IL)-2. ${ }^{12,13}$ The secondary phase of infection is characterized by the anti-inflammatory state. It is in this state that activated Th2 cells secrete cytokines such as IL- 4 and IL-10. ${ }^{12,14}$ It is this state 
of depressed immune activation that leads to secondary infections such as bacterial coinfections and CMV reactivation. ${ }^{15}$

The influenza virus has developed its own host of mechanisms to counteract the activity of major antiviral cytokines such as INF- $\gamma$. Influenza proteins such as NS-1, which antagonize and inhibit the actions of IFN, PBF-F2 proteins that inhibit IFN induction, viral polymerase that inhibits IFN function, and M2 protein prevents TLR induction. ${ }^{16}$

Viral infections can trigger the dysregulation of the immune system by inducing a massive cytokine response. This cytokine storm can cause endothelial damage and dysfunction, deregulation of coagulation, and, consequently, alteration of microvascular permeability, tissue edema, and shock. ${ }^{17}$ In severe influenza, this vascular hyperpermeability can lead to acute lung injury, multiorgan failure, and encephalopathy. ${ }^{16}$ Different strains of influenza elicit different immune responses. It has been suggested that H5N1 may cause a higher viral load and hypercytokinemia. ${ }^{18,19}$ It has also been shown that H5N1 viral replication is not confined to the respiratory tract but also occurs in the intestine. ${ }^{20}$

\section{Clinical Features}

Influenza is an acute respiratory disease characterized in its full form by the sudden onset of respiratory and systemic symptoms, with high fever as a characteristic feature. ${ }^{21}$ While influenza A and B are the most common causes of this influenzalike illness (ILI), other pathogens such as influenza C, parainfluenza, respiratory syncytial virus (RSV), and Mycoplasma pneumoniae can also cause it. ${ }^{21}$

Different strains have been found to elicit different clinical features. Influenza A H3N2 infection has been found to be more severe than $\mathrm{H} 1 \mathrm{~N} 1$ or B in terms of fever, leukopenia, or C-reactive protein, whereas gastrointestinal symptoms seem to be more common in influenza B. ${ }^{22}$ However, another study found similar clinical manifestations and outcomes among adults with influenza $A$ and those with influenza $B .^{23}$ Wie et al described that leukopenia or thrombocytopenia was found to occur more often in patients with influenza $B$; however, the rate of hospitalization and hospital length of stay (LOS) were found to be higher in those with influenza $A$ (H3N2). In addition, the proportion of males to females and of elderly population were significantly higher for patients with influenza A compared with those with influenza B. ${ }^{24}$

\section{Viral Pneumonia}

Viral pneumonia is the most common complication of influenza infection. A study in 2015 looked at risk factors for developing pneumonia from influenza infection. Among 4,765 adults hospitalized with influenza, 1,392 (29\%) had pneumonia. In multivariable analysis, factors associated with pneumonia were age $\geq 75$ years, Caucasian race, nursing home residence, chronic lung disease, immunosuppression, and asthma. Patients with pneumonia were significantly more likely to require ICU admission (27 vs. 10\%), require invasive mechanical ventilation (MV; 18 vs. 5\%), and have an increased risk of death (9 vs. $2 \%) .{ }^{25}$ Influenza-associated pneumonia may be either primary viral influenza pneumonia, secondary bacterial pneumonia, or influenza-bacterial coinfection. Patients with pneu- monia are significantly more likely to have a hospital LOS greater than 1 week, require ICU admission, require MV, and have an increased risk of death. ${ }^{25}$

Among patients with viral pneumonia, factors independently associated with a poor outcome (defined as ICU admission, the need for MV, or death) included nursing home residence, chronic lung disease, cardiovascular disease, renal disease, and immunosuppression. Of note, older age was found as a protective factor among patients hospitalized with pneumonia. $^{25}$

\section{Risk Factors for Severe Influenza Infection}

Coleman et al examined the risk factors for serious outcomes associated with influenza illness in high-income countries (HICs) versus low- and middle-income countries (LMICs). They found that patients more likely to suffer severe outcomes (ICU admission, and/or death) were more vulnerable populations such as those affected with comorbidities (malignancies, immune-suppressing conditions, and renal, cardiac, and lung diseases including tuberculosis). ${ }^{26}$ Another important risk factor is pregnancy. Pregnant women in LMICs were at 66 percent increased risk of severe outcome compared with other patients with influenza; however, there was no increased risk for pregnant women in HICs. Similarly, patients with HIV were not at an increased risk of severe outcome in HICs; however, they were at an increased risk of LMICs. ${ }^{26}$

\section{Coinfection}

While treatment of CAP has traditionally focused on bacterial etiology, more recent research has indicated that viruses may be involved in 15 to $30 \%$ of CAP..$^{27-29}$ Rapid diagnostic testing is thus of vital importance in identifying the offending pathogen, initiating targeted treatment, and preventing the inappropriate use of antibiotics. Systematic reviews and meta-analyses found that respiratory viruses are detected in approximately $22 \%$ of CAP patients. ${ }^{30,31}$ Influenza is consistently the most common viral pathogen identified. There was a trend toward lower identification of viral pathogens in studies published from 2001 to 2009 as opposed to studies published after $2010 .^{30}$ In this study, the viruses most commonly identified in European adult patients with CAP from more to less frequent were influenza $(A \& B)$, rhinovirus, coronavirus, parainfluenza, human metapneumovirus, RSV, and adenovirus.

\section{Bacterial Coinfection}

The frequency of bacterial coinfection in patients with influenza was reported as being between 11 and 35\%. Streptococcus pneumoniae and $S$. aureus were the most common pathogens accounting for 35 and $28 \%$ of identified coinfecting bacteria, respectively. Influenza infection has been associated with 11 to $14 \%$ of pneumococcal pneumonia during influenza season and 5 to $6 \%$ overall. ${ }^{32}$ In addition, Grabowska et al found that 6 to $10 \%$ of cases of invasive pneumococcal disease were associated with influenza per year or 12 to $20 \%$ per influenza season. ${ }^{33}$ Several other pathogens such as nonfermenting gram-negative bacilli have also been identified as causing coinfections. ${ }^{34}$ There 


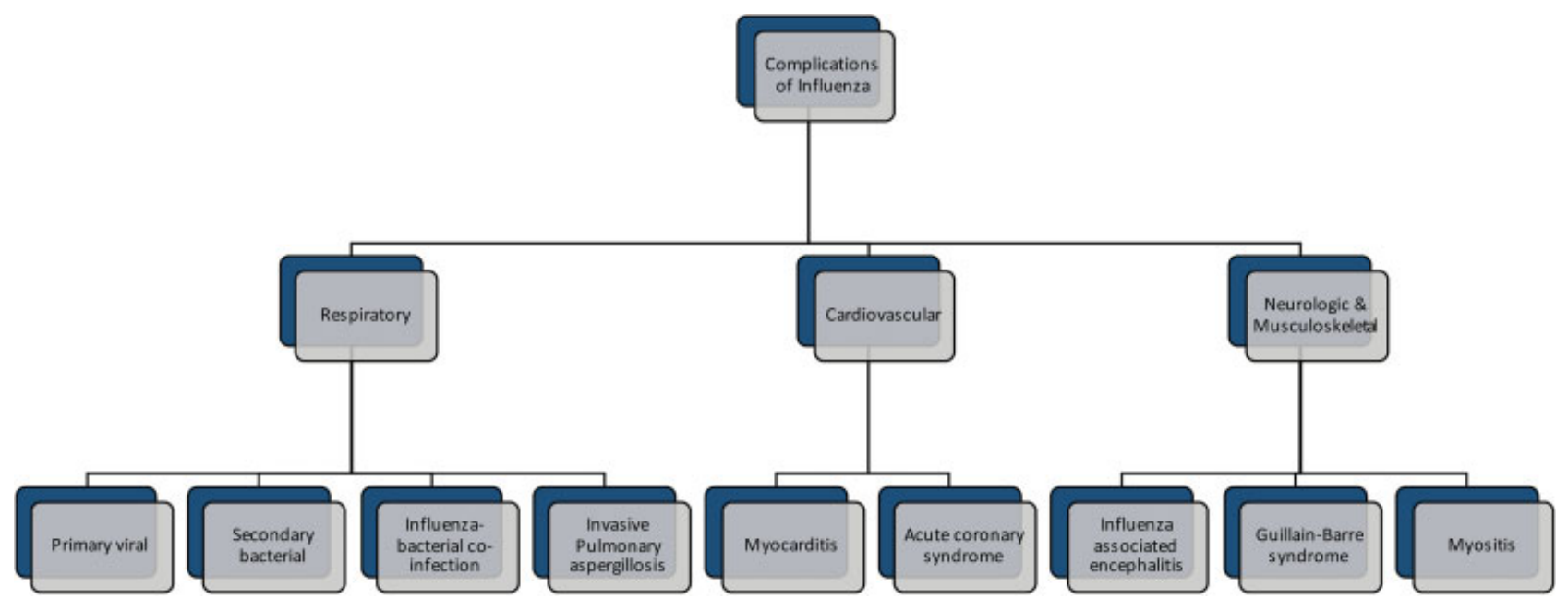

Fig. 1 Complication of influenza infection in patients admitted to hospital settings.

are several reasons for propensity to bacterial coinfection that are complex and not yet fully explained ( - Fig. 1). There appear to be organism-specific interactions with $S$. aureus and $S$. pneumoniae that cause a higher rate of infection with these bacteria. ${ }^{16} \mathrm{~A}$ recent multicenter study by MartinLoeches et al, which included almost 3,000 critically ill patients, has shown that coinfections are occurring more frequently since 2009. Coinfection was more likely to occur in older and immunosuppressed patients. In addition, coinfection was an independent risk factor for ICU mortality, 28-day mortality, and hospital mortality. ${ }^{35}$

Another recent multicenter study analyzing immunosuppressed patients found that the category of infectious etiology of respiratory failure (influenza, noninfluenza, influenza plus coinfection, and noninfectious) was associated with ICU but not hospital mortality. ${ }^{36}$

\section{Invasive Pulmonary Aspergillosis}

A Spanish group in 2011 reported the first cases of invasive aspergillosis (IA) when patients were admitted to the ICU due to influenza infections. ${ }^{37}$ A retrospective multicenter cohort study by Schauwvlieghe et al examined the incidence of IA in patients admitted to the ICU with severe influenza. They found that IA was present in 32\% (38/117) of immunocompromised patients and 14\% (45/315) immunocompetent patients. ${ }^{38}$ The incidence of IA was almost equal in patients with influenza $A$ and those with influenza B. In addition, they compared 315 nonimmunocompromised influenza-positive patients with an equal number of nonimmunocompromised influenza-negative patients with severe CAP. They found that influenza was "independently associated with invasive pulmonary aspergillosis." ${ }^{38}$

\section{Treatment}

Data on the use of NA inhibitors (NAI) in intensive care patients are limited. A meta-analysis by Muthuri et al showed that early initiation ( $\leq 2$ days after symptom onset) of NAI treatment versus late initiation (treatment commenced $>2$ days after symptom onset) reduced mortality and requirement of venti- latory support but did not reduce the incidence of influenzarelated pneumonia in patients with influenza A(H1N1)pdm09. They found that among the critically ill patient population, NAI use was associated with a reduction in mortality compared with no therapy (odds ratio [OR]: 0.72; 95\% confidence interval [CI]: 0.56-0.94) and that early use of NAIs was associated with a reduction in mortality compared with late initiation of treatment (OR: 0.62; 95\% CI: 0.49-0.77). ${ }^{39}$

The impact of early ( $\leq 2$ days of symptom onset) versus late ( $>2$ days after symptom onset) administration of oseltamivir was also examined by Rodrigo et al. This was a prospective observational study of adult patients admitted to ICU with microbiologically confirmed influenza A during the 2009 influenza season in Spain. The study included 657 patients. In the entire patient population, there was a nonsignificant difference in ICU mortality in patients who received early treatment (EL) versus late treatment (LT) (OR: 1.45; 95\% CI: $0.96-2.21)^{40}$

A further subgroup analysis looked at the 404 patients who required MV. Of these, 385 patients received effective antiviral therapy. ET was initiated in $20.5 \%$ of patients $(n=79)$, whereas LT was initiated in $79.5 \%$ of patients $(n=306)$. LT compared with ET was associated with increased ICU LOS ( $22.7 \pm 16.7$ vs. $18.4 \pm 14.2$ days; $p=0.03$ ), hospital LOS (34.0 \pm 20.3 vs. $27.2 \pm 18.2$ days; $p=0.001)$, and MV days $(17.4 \pm 15.2$ vs. $14.0 \pm 12.4 ; p=0.04)$. ICU mortality was also higher with LT (34.3\%) than with ET (21.5\%; OR: 1.9; 95\% CI: 1.06-3.41). These findings suggest that early oseltamivir administration was associated with improved outcomes in ventilated patients during the 2009 H1N1 pandemic. ${ }^{40}$ A study by Lytras et al examined the effect of early oseltamivir treatment on mortality in critically ill patients infected with influenza A/H1N1, A/H2N3, and influenza B over eight seasons from 2010 to 2011 and from 2017 to 2018 . This was a cohort study including 1,330 patients, of whom 622 (46.8\%) died in the ICU. Among patients with influenza $\mathrm{A} / \mathrm{H} 3 \mathrm{~N} 2$, there was a reduction in mortality observed in the ET group compared with the LT group ( 33.7 vs. $48.4 \%$ respectively; $p=0.029$ ). Median LOS in the ICU was also shorter in the ET group (12 vs. 15 days; 
$p=0.003$ ). In this study, no significant effect of early versus late oseltamivir was observed for influenza A/H1N1 or influenza $B{ }^{41}$

Concerns regarding the absorption of oseltamivir in critically ill patients have led to several studies of the use of highdose oseltamivir. The standard dose of $75 \mathrm{mg}$ twice daily was found to achieve similar plasma levels in critically ill patients compared with ambulatory patients. These concentrations were far in excess of concentrations required to maximally inhibit NA activity of the virus. ${ }^{42}$ High-dose oseltamivir has also been shown to achieve similar effects to standard dose oseltamivir in terms of mortality and viral RNA. ${ }^{43}$ While 5 days of oseltamivir has been the standard duration of therapy in ambulatory patients, it has been suggested that therapy should be continued in patients who remain in a critical state after 5 days of treatment. ${ }^{44,45}$ The intravenous NAI, peramivir, has been shown to be as effective as oral oseltamivir in terms of mortality and length ICU stay. ${ }^{46}$ It could thus be considered as an alternative in those unable to take oral oseltamivir.

Other potential treatments have been investigated. A systematic review and meta-analysis by Mair-Jenkins et al examined studies on convalescent plasma for the treatment of severe acute respiratory infections of viral etiology. It included a post hoc meta-analysis of pooled data from eight comparative studies: two studies on SARS-CoV (severe acute respiratory syndrome-coronavirus) infection, two on influenza $A(H 1 N 1)$ pdm09 infection, one on avian influenza $A(H 5 N 1)$ infection, and three on Spanish influenza $A(H 1 N 1)$ infection. The results from this meta-analysis suggest that convalescent plasma may have an impact on reducing mortality and viral load in patients with severe acute respiratory infections of viral etiology. ${ }^{44}$ There have been case reports of a rapid reduction in detectable viral load in patients with influenza A (H5N1) treated with convalescent plasma without significant serious events. ${ }^{47-49}$

A prospective cohort study conducted during the H1N1 2009 pandemic included 93 patients with severe infection requiring intensive care. Twenty patients $(21.5 \%)$ received convalescent plasma. Mortality in the treatment group was significantly lower ( 20.0 vs. $54.8 \% ; p=0.01$ ). Respiratory tract viral load, IL-6, Il-10, and TNF- $\alpha$ were also significantly lower in the treatment group. ${ }^{50}$

Different studies have tried to analyze the association of the role of adjuvant immunomodulatory agents for the treatment of severe influenza, including corticosteroids, statins, macrolides, nonimmune intravenous immunoglobulin, $\mathrm{N}$-acetylcysteine, pamidronate, nitazoxanide, chloroquine, antic5a antibody, IFNs, human mesenchymal stromal cells, mycophenolic acid, peroxisome proliferator-activated receptors agonists, nonsteroidal anti-inflammatory agents, and mesalazine, with the role of plasmapheresis and hemoperfusion as a rescue therapy. ${ }^{51}$ While none of these immunomodulatory therapies have shown any benefit, we have to acknowledge that the evidence is unclear due to limited published database on randomized controlled trials (RCTs). In critically ill patients, two of these coadjuvant treatments have gathered most of the attention: macrolides and corticosteroids. The use of macrolides was analyzed in a large cohort of patients with the use of a propensity score analysis, and their use was not associated with any benefit in critically ill patients. ${ }^{52}$

A Cochrane review (originally published in 2016 followed by updated review in 2019) included 30 studies with 99,224 participants and found that corticosteroid therapy was associated with increased mortality. A similar increase in risk of mortality was seen in a stratified analysis of studies reporting adjusted estimates. An association between corticosteroid therapy and increased mortality was also seen in a pooled analysis of six studies that reported adjusted hazard ratios (HRs) (HR: 1.49; 95\% CI: $1.09-2.02 ; I^{2}=69 \%$ ). Increased odds of hospital-acquired infection related to corticosteroid therapy were found in a pooled analysis of seven studies (pooled OR: 2.74; 95\% CI: $1.51-4.95 ; I^{2}=90 \%$ ); all were unadjusted estimates, and the data was graded as of very low certainty. Limitations of the review included inconsistent reporting of variables and low quality of data specific to mortality. ${ }^{53}$

Corticosteroids have been shown in several meta-analyses to be associated with increased mortality. ${ }^{54-56}$ As a caveat, it has been suggested that corticosteroids may have been given to the sicker patients in the studies included in these metaanalyses, patients in whom the mortality was going to be higher anyway. The authors of these meta-analyses also concluded that there is a lack of sufficiently powered randomized trials examining the issue.

Regarding extracorporeal life support, the 2009 pandemic saw an increase in frequency of the use of venovenous extracorporeal membrane oxygenation (ECMO) as a rescue therapy in patients with severe acute respiratory distress syndrome (ARDS). A systematic review by Sukhal et al examined the use of ECMO in severe influenza infection. While there is a lack of randomized trials in the study, their results do suggest a benefit from the initiation of ECMO in severe respiratory failure secondary to H1N1 influenza. ${ }^{57}$

\section{Nonrespiratory Complications}

\section{Cardiovascular Complications}

The incidence of myocarditis in patients with influenza may be as high as $10 \%{ }^{58}$ It commonly occurs between days 4 and 7 after the onset of influenza symptoms. ${ }^{59}$ Myocarditis is diagnosed based on a combination of symptoms, elevated cardiac enzymes, and echocardiographic findings. Myocarditis is not limited to those with severe respiratory manifestations of influenza. Symptoms related to myocarditis, such as chest pain, dyspnea, and syncope, may have been the cause of presentation to hospital in the first instance. ${ }^{59}$ The clinical manifestations range from subclinical myocarditis to sudden death, new-onset atrial or ventricular arrhythmias, complete heart block, heart failure, pericardial effusion, cardiac tamponade, and acute myocardial infection (AMI)-like syndromes. ${ }^{58,60}$ The most common complication is congestive heart failure diagnosed by global hypokinesis on echo/MRI (magnetic resonance imaging), which has been reported in 84\% (37/44) of patients with influenza-associated myocarditis. The majority (70\%; 26/37) of those who had myocarditis-related reduced ejection fraction (ranging from 8 to $50 \%$ ) experienced resolution 
of their systolic function, typically within 20 days of the onset of dysfunction. $^{60}$

Many patients who develop influenza-related myocarditis require advanced cardiac support therapies such as intraaortic balloon pumps and ECMO. Early diagnosis is paramount, and mortality has been reported as approximately $23 \% .{ }^{60}$ It is important to note that reduced ejection fraction in the absence of myocarditis has been reported in influenza infection. Right ventricular dysfunction appears to be more common than left ventricular dysfunction and is over and above what would normally be expected in patients with ARDS. ${ }^{61}$

A meta-analysis of case-control studies by Barnes et al found that recent influenza infection, ILI, or respiratory tract infection was significantly more likely in AMI cases (pooled OR: 2.01; 95\% CI: 1.47-2.76). In addition, influenza vaccination was negatively associated with AMI (pooled OR: $0.71 ; 95 \% \mathrm{CI}: 0.56-0.91) .{ }^{49}$ These findings are in keeping with other studies on the association between influenza and $A M I,{ }^{62,63}$ and influenza vaccination and AMI. ${ }^{64,65}$ The pathogenesis may be due to several mechanisms, including increased coronary and systemic inflammatory activity that drives procoagulant processes, dominant prothrombotic conditions, increased biomechanical stress on coronary arteries, variations in the coronary arterial tone, disturbed hemodynamic hemostasis, and altered metabolic balance. ${ }^{66}$

Other less common cardiovascular complications are dysrhythmias and pericarditis. The most commonly reported cardiac arrhythmias associated with influenza are atrioventricular conduction block and ventricular fibrillation. These are usually due to underlying fulminant myocarditis. ${ }^{58}$ Although pericarditis is a recognized complication of influenza infection, it is often mild and uncomplicated. ${ }^{58}$

\section{Neurologic Complications}

Influenza-associated encephalitis or encephalopathy is a syndrome characterized by an impaired level of consciousness occurring within a few days of influenza infection. The most common neurologic symptoms are confusion and seizures. MRI and computed tomography (CT) commonly produce abnormal findings, with lesions being located throughout the brain with no characteristic patterns or areas of focus. ${ }^{67}$

While the most common associated agents in GuillainBarre's syndrome (GBS) are Campylobacter jejuni, M. pneumoniae, and EBV, 60 to $70 \%$ of cases of GBS do not have a clear etiology identified. ${ }^{60}$ Influenza virus has been proposed as an important and underrecognized cause of GBS. Numerous studies have found a significantly increased risk of GBS in the months following influenza infection. ${ }^{68,69}$

In addition to neurologic complications, elevation in creatine kinase (CK) has been suggested as a biomarker of the severity of influenza infection. In a study by Borgatta et al of cases of influenza A pH1N1 infection in 2009, CK $\geq 500 \mathrm{UI} / \mathrm{L}$ was associated with greater renal dysfunction and requirement of renal replacement therapy. Increase of CK $\geq 1,000 \mathrm{UI} / \mathrm{L}$ was associated with greater intubation risk, longer duration of MV, and 5 extra days of ICU and hospital LOS. ${ }^{70}$ Rhabdomyolysis, although rare, has been reported in association with influenza infection. ${ }^{60}$

\section{Mortality}

The hospitalization fatality risk, defined as the probability of death among H1N1pdm09 patients who required hospitalization for medical reasons, was examined in a systematic review and meta-analysis by Wong et al. Crude estimates of the HFR ranged from 0 to $52 \%$. There was, however, substantial heterogeneity of studies. Higher estimates came from tertiary-care referral hospitals in countries with lower gross domestic products (GDPs). Countries with lower GDPs were hypothesized to have had higher thresholds for hospital admission and ICU treatment. The hospitalized cases may have been more severe than in countries with higher GDPs. The risk of death would thus have been higher. In wealthy countries, the estimate was 1 to $3 \%$ in all settings. ${ }^{71}$ A systematic review by Khandaker et al found a confirmed case fatality rate of $1.1 \%$ in HICs and $4.6 \%$ in upper- and lowermiddle income countries during the pandemic of $2009 .{ }^{72}$ The mortality rate for critically ill patients with severe influenza requiring admission to the ICU during the 2009 to 2010 pandemic was approximately $26 \%$ in HICs, $37 \%$ in uppermiddle income countries, and $58 \%$ in lower-middle income countries. $^{73}$

\section{Other Severe Nosocomial Viral Infection in Immunocompromised Patients}

Immunoparalysis following the initial proinflammatory response to physiological insult (sepsis, trauma, etc.) is frequent in nonimmunocompromised ICU patients. ${ }^{74}$ One of the consequences of this immunoparalysis is the reactivation of latent viruses, with herpesviridae (mostly HSV, CMV, and EBV) being the most frequent.

\section{Herpes Simplex Virus}

Numerous studies have evaluated HSV reactivation in ICU patients $^{75-79}$ (- Table 1). To summarize these studies, HSV reactivation starts in the oropharyngeal tract in 20 to $50 \%$ of ICU patients, 3 to 5 days after ICU admission, followed by a descending lower respiratory tract colonization in 20 to $65 \%$ of mechanically ventilated patients, after a median of 7 days of MV and with a peak of virus load 12 days after MV start. ${ }^{80}$ In some patients, a true lung infection (HSV bronchopneumonitis) can occur after a median of 14 days of MV; in a study evaluating 201 patients with prolonged ( $>4$ days) MV, Luyt et al found that $20 \%$ of them had HSV bronchopneumonitis with cytological and/or histological signs of deep lung infection. ${ }^{76}$ Distinguishing HSV lung reactivation from infection may be difficult; indeed, lung infection is defined by clinical signs, presence of HSV, and cytological/histological criteria, that is, HSV-specific nuclear inclusions on cells collected during bronchoalveolar lavage (BAL). ${ }^{76}$ However, this technique is difficult to implement and may be subjective. Virus load in BAL fluid, with a cutoff set at $10^{5}$ copies $/ \mathrm{mL}$, may be a good alternative. ${ }^{76,78,81}$ 
Table 1 Main studies having evaluated HSV, CMV, and EBV reactivation in ICU patients

\begin{tabular}{|c|c|c|c|}
\hline Study & Population & $\begin{array}{l}\text { Virus reactivation } \\
\text { frequency, } N(\%)\end{array}$ & Method of detection \\
\hline \multicolumn{4}{|l|}{ HSV reactivation } \\
\hline Bruynseels et al, $2003^{75}$ & $\begin{array}{l}764 \text { patients, } 361 \text { of them } \\
\text { receiving MV }\end{array}$ & $\begin{array}{l}169 / 764(22 \%) \text { in the throat } \\
58 / 361(19 \%) \text { in distal airways }\end{array}$ & Viral culture \\
\hline Ong et al, $2004^{77}$ & 393 receiving MV & $106(27 \%)$ & PCR \\
\hline Luyt et al, $2007^{76}$ & $\begin{array}{l}201 \text { patients ventilated for }>4 \mathrm{~d} \text {, } \\
\text { suspected of having developed VAP }\end{array}$ & $\begin{array}{l}109(54 \%) \text { in the throat } \\
129(64 \%) \text { in distal airways }\end{array}$ & PCR, viral culture \\
\hline Linssen et al, $2008^{78}$ & $\begin{array}{l}260 \text { patients suspected of having } \\
\text { developed VAP }\end{array}$ & $99(32 \%)$ in distal airways & PCR \\
\hline Costa et al, $2012^{79}$ & $\begin{array}{l}127 \text { patients suspected of having } \\
\text { developed VAP }\end{array}$ & $38(31 \%)$ in distal airways & PCR \\
\hline \multicolumn{4}{|l|}{ CMV blood reactivation } \\
\hline Jaber et al, $2005^{85}$ & 237 patients with fever & $40(17 \%)$ & pp65 antigen \\
\hline Limaye et al, $2008^{86}$ & 120 CMV-seropositive patients & $39(33 \%)$ & PCR \\
\hline Chiche et al, $2009^{87}$ & 242 mechanically ventilated patients & $33(14 \%)$ & pp65 antigen \\
\hline Limaye et al, $2017^{88}$ & $\begin{array}{l}72 \text { CMV-seropositive patients } \\
\text { included in the placebo arm }\end{array}$ & $28(39 \%)$ & PCR \\
\hline \multicolumn{4}{|l|}{ CMV lung disease } \\
\hline Papazian et al, $1996^{89}$ & $\begin{array}{l}86 \text { patients with acute respiratory } \\
\text { failure or VAP }\end{array}$ & $25(29 \%)$ & $\begin{array}{l}\text { Histology } \\
\text { (autopsy or biopsy) }\end{array}$ \\
\hline Papazian et al, $2007^{90}$ & 100 patients with unexplained ARDS & $30(30 \%)$ & Histology (biopsy) \\
\hline Chiche et al, $2009^{87}$ & 242 mechanically ventilated patients & $11(5 \%)$ & Viral culture \\
\hline \multicolumn{4}{|l|}{ EBV reactivation } \\
\hline Tachikawa et al, $2014^{93}$ & 87 patients with unexplained ARDS & $16(18 \%)$ in BAL fluid & PCR in BAL fluid \\
\hline Libert et al, $2015^{94}$ & $\begin{array}{l}86 \text { EBV-seropositive patients } \\
\text { with ICU LOS } \geq 5 \text { days }\end{array}$ & $\begin{array}{l}61(71 \%) \text { EBV detection } \\
\text { in the blood }\end{array}$ & PCR in blood \\
\hline Ong et al, $2017^{95}$ & $\begin{array}{l}329 \text { immunocompetent patients } \\
\text { with septic shock }\end{array}$ & $\begin{array}{l}157(48 \%) \text { EBV detection } \\
\text { in the blood }\end{array}$ & PCR in blood \\
\hline
\end{tabular}

Abbreviations: ARDS, acute respiratory distress syndrome; BAL, bronchoalveolar lavage; CMV, cytomegalovirus; EBV, Epstein-Barr virus; HSV, herpes simplex virus; ICU, intensive care unit; LOS, length of stay; MV, mechanical ventilation; PCR, polymerase chain reaction; VAP, ventilator-associated pneumonia.

HSV reactivation is associated with a poor outcome; a meta-analysis showed that HSV reactivation was associated with mortality (OR: 1.8 ; $95 \% \mathrm{CI}: 1.2-2.6)^{82}$; however, the exact significance of HSV reactivation (i.e., bystander or true pathogen with its own morbidity/mortality) remains to be determined. To date, only one small randomized controlled study using prophylactic acyclovir failed to demonstrate any clinical beneficial effect of antiviral treatment. ${ }^{83}$ One retrospective study found an improvement in mortality in HSV carriers having received acyclovir, ${ }^{84}$ and one prospective study failed to show any beneficial effect of acyclovir in patients with HSV bronchopneumonitis. ${ }^{76}$

\section{Cytomegalovirus}

Blood and/or lung CMV reactivation may occur in ICU patients $^{85-90}$ (-Table 1). Blood CMV reactivation occurs in one-third of CMV-seropositive ICU patients after a median of 4 to 12 days after admission. Lung CMV reactivation/infection is less frequent, occurring in $5 \%$ of mechanically ventilated patients ${ }^{87}$; but the frequency can reach $30 \%$ in patients with acute lung injury without an obvious cause ${ }^{89,90}$ A recent meta-analysis showed that $27 \%$ of ICU may experience CMV reactivation, whatever be the site (blood or lung) of reactivation. ${ }^{91}$ Although CMV blood reactivation is associated with poor prognosis, ${ }^{82,91}$ no study has evaluated the relationship between CMV blood reactivation and CMV disease (i.e., organ involvement). CMV lung disease has been almost exclusively diagnosed using histology on lung biopsies or autopsies, ${ }^{89,90}$ whereas the use of cytology on BAL-collected cells (looking for CMV-specific inclusions) or quantitative polymerase chain reaction (PCR) has never been investigated.

Like HSV, CMV reactivation is associated with a poor outcome; a recent meta-analysis showed that CMV reactivation in nonimmunocompromised patients was associated with mortality (OR: 1.72; 95\% CI: 1.04-2.85). ${ }^{91}$ Moreover, Limaye et al found that CMV virus load was associated with mortality: the higher the virus load, the higher the mortality. ${ }^{86}$ However, again, the exact significance of CMV reactivation is not known; it could be a marker of severity (bystander) or a pathogen with true morbidity and/or mortality. 
Two randomized controlled trials evaluating the effectiveness of prophylactic anti-CMV treatment in CMV-positive ICU patients were recently published. ${ }^{88,92}$ The first one evaluated prophylactic valganciclovir or valacyclovir, as compared with a placebo, to decrease $\mathrm{CMV}$ reactivation. While inclusions in the valacyclovir arm were prematurely stopped due to unexplained increased mortality, patients treated with valganciclovir had less CMV reactivation than, but similar outcomes to, placebo-treated patients. ${ }^{92}$ In the second one, a double-blind, placebo-controlled trial, the authors evaluated prophylactic ganciclovir to reduce IL-6 level (measured 14 days after randomization). Although ganciclovir failed to reduce IL-6 level at day 14 , as compared with placebo, there was a trend toward increased ventilator-free days at day 28 in patients having received ganciclovir, but with similar mortality. ${ }^{88}$

\section{Epstein-Barr Virus}

Recently, some authors investigated the frequency of EBV DNA detection in BAL fluid ${ }^{93}$ or in the blood ${ }^{94,95}$ using PCR (-Table 1). They found that EBV DNA detection is frequent in ICU patients and seems to be associated with mortality. ${ }^{94,95}$ Again, the exact significance of EBV detection in ICU patients has to be determined, and thus to consider a specific treatment against EBV in ICU patients with EBV DNA detection is to date premature.

In summary, herpesviridae reactivations are frequent in ICU patients and associated with mortality. However, the exact significance of herpesviridae reactivation is poorly understood. In some cases, it is associated with a true disease; but in some cases, the relationship between viral reactivation and viral disease is not established. In these latter cases, whereas a specific antiviral treatment may improve outcome remains to be determined. To date, neither prophylactic acyclovir to prevent HSV reactivation nor prophylactic ganciclovir to prevent CMV reactivation can be recommended; preemptive treatment with acyclovir in patients with oropharyngeal HSV reactivation or ganciclovir in patients with CMV blood reactivation is under investigation (PTH [Preemptive Treatment for Herpesviridae] study, Clinical Trials $n^{\circ}$ NCT02152358). Curative treatment of HSV bronchopneumonitis or CMV lung disease is based on expert opinions in patients with either cytological/histological proofs of lung involvement, high viral load, or specific clinical and biological patterns suggestive of CMV. ${ }^{96,97}$

\section{Summary}

Patients in ICU are at risk of viral infections. In immunocompetent patients, the most common viral infections are respiratory, and influenza should be considered in patients with severe respiratory failure being admitted to the ICU. Seasonality and coinfection are two important features when considering influenza as a pathogen in critically ill patients.

Viral infections are more frequent in immunosuppressed patients. Solid organ and hematopoietic stem cell transplant recipients, as well as those receiving chemotherapy for a malignant hematological disease are clearly predisposed to a variety of viral infections, both common and opportunistic.
The patient may have acquired these infections from the community, the donor organ (donor-derived infections), and/or reactivation of an endogenous latent virus. HSV, especially CMV and EBV, is among the most common of the opportunistic viral pathogens affecting these patients in addition to respiratory viruses. In recent years, several studies have found that these opportunistic infections can also cause the development of an infection in immunocompetent patients with some transient degree of induced immunosuppression.

\section{Conflict of Interest}

None.

\section{References}

1 Cohen M, Zhang XQ Senaati HP, et al. Influenza A penetrates host mucus by cleaving sialic acids with neuraminidase. Virol J 2013; $10: 321$

2 WHO. A revision of the system of nomenclature for influenza viruses: a WHO memorandum. Bull World Health Organ 1980;58 (04):585-591

3 Petrova VN, Russell CA. The evolution of seasonal influenza viruses. Nat Rev Microbiol 2018;16(01):47-60

4 Ziegler T, Mamahit A, Cox NJ. 65 years of influenza surveillance by a World Health Organization-coordinated global network. Influenza Other Respir Viruses 2018;12:558-565

5 Webster RG, Bean WJ, Gorman OT, Chambers TM, Kawaoka Y. Evolution and ecology of influenza A viruses. Microbiol Rev 1992; 56(01):152-179

6 Jagadesh A, Salam AA, Mudgal PP, Arunkumar G. Influenza virus neuraminidase (NA): a target for antivirals and vaccines. Arch Virol 2016;161(08):2087-2094

7 Taubenberger JK, Morens DM. 1918 Influenza: the mother of all pandemics. Emerg Infect Dis 2006;12(01):15-22

8 Patterson KD, Pyle GF. The geography and mortality of the 1918 influenza pandemic. Bull Hist Med 1991;65(01):4-21

9 Johnson NP, Mueller J. Updating the accounts: global mortality of the 1918-1920 "Spanish" influenza pandemic. Bull Hist Med 2002;76(01):105-115

10 Bouvier NM, Palese P. The biology of influenza viruses. Vaccine 2008;26(Suppl 4):D49-D53

11 Gambotto A, Barratt-Boyes SM, de Jong MD, Neumann G, Kawaoka Y. Human infection with highly pathogenic H5N1 influenza virus. Lancet 2008;371(9622):1464-1475

12 Hotchkiss RS, Karl IE. The pathophysiology and treatment of sepsis. N Engl J Med 2003;348(02):138-150

13 Brown MA, Jones WK. NF-kappaB action in sepsis: the innate immune system and the heart. Front Biosci 2004;9:1201-1217

14 Russell JA. Management of sepsis. N Engl J Med 2006;355(16): 1699-1713

15 Florescu DF, Kalil AC. Cytomegalovirus infections in non-immunocompromised and immunocompromised patients in the intensive care unit. Infect Disord Drug Targets 2011;11(04):354-364

16 Florescu DF, Kalil AC. The complex link between influenza and severe sepsis. Virulence 2014;5(01):137-142

17 Steinberg BE, Goldenberg NM, Lee WL. Do viral infections mimic bacterial sepsis? The role of microvascular permeability: a review of mechanisms and methods. Antiviral Res 2012;93(01):2-15

18 de Jong MD, Simmons CP, Thanh TT, et al. Fatal outcome of human influenza A (H5N1) is associated with high viral load and hypercytokinemia. Nat Med 2006;12(10):1203-1207

19 Peiris M. Pathogenesis of avian flu H5N1 and SARS. Novartis Found Symp 2006;279:56-60, discussion 60-65, 216-219

20 Uiprasertkul M, Puthavathana P, Sangsiriwut K, et al. Influenza A H5N1 replication sites in humans. Emerg Infect Dis 2005;11(07): 1036-1041 
21 Taubenberger JK, Morens DM. The pathology of influenza virus infections. Annu Rev Pathol 2008;3:499-522

22 Kaji M, Watanabe A, Aizawa H. Differences in clinical features between influenza A H1N1, A H3N2, and B in adult patients. Respirology 2003;8(02):231-233

23 Hong KW, Cheong HJ, Song JY, Noh JY, Yang TU, Kim WJ. Clinical manifestations of influenza A and B in children and adults at a tertiary hospital in Korea during the 2011-2012 season. Jpn J Infect Dis 2015;68(01):20-26

24 Wie SH, So BH, Song JY, et al. A comparison of the clinical and epidemiological characteristics of adult patients with laboratoryconfirmed influenza A or B during the 2011-2012 influenza season in Korea: a multi-center study. PLoS One 2013;8(05): e62685

25 Garg S, Jain S, Dawood FS, et al. Pneumonia among adults hospitalized with laboratory-confirmed seasonal influenza virus infection-United States, 2005-2008. BMC Infect Dis 2015;15:369

26 Coleman BL, Fadel SA, Fitzpatrick T, Thomas SM. Risk factors for serious outcomes associated with influenza illness in high- versus low- and middle-income countries: systematic literature review and meta-analysis. Influenza Other Respir Viruses 2018;12(01): 22-29

27 Johnstone J, Majumdar SR, Fox JD, Marrie TJ. Viral infection in adults hospitalized with community-acquired pneumonia: prevalence, pathogens, and presentation. Chest 2008;134(06): 1141-1148

28 Pavia AT. What is the role of respiratory viruses in communityacquired pneumonia?: what is the best therapy for influenza and other viral causes of community-acquired pneumonia? Infect Dis Clin North Am 2013;27(01):157-175

29 Jain S, Self WH, Wunderink RG, et al; CDC EPIC Study Team. Community-acquired pneumonia requiring hospitalization among U.S. adults. N Engl J Med 2015;373(05):415-427

30 Alimi Y, Lim WS, Lansbury L, Leonardi-Bee J, Nguyen-Van-Tam JS. Systematic review of respiratory viral pathogens identified in adults with community-acquired pneumonia in Europe. JClin Virol 2017;95:26-35

$31 \mathrm{Wu} \mathrm{X}$, Wang $\mathrm{Q}$, Wang $\mathrm{M}$, et al. Incidence of respiratory viral infections detected by PCR and real-time PCR in adult patients with community-acquired pneumonia: a meta-analysis. Respiration 2015;89(04):343-352

32 Walter ND, Taylor TH, Shay DK, et al; Active Bacterial Core Surveillance Team. Influenza circulation and the burden of invasive pneumococcal pneumonia during a non-pandemic period in the United States. Clin Infect Dis 2010;50(02):175-183

33 Grabowska K, Högberg L, Penttinen P, Svensson A, Ekdahl K. Occurrence of invasive pneumococcal disease and number of excess cases due to influenza. BMC Infect Dis 2006;6:58

34 Klein EY, Monteforte B, Gupta A, et al. The frequency of influenza and bacterial coinfection: a systematic review and meta-analysis. Influenza Other Respir Viruses 2016;10(05):394-403

35 Martin-Loeches I, J Schultz M,Vincent JL, et al. Increased incidence of co-infection in critically ill patients with influenza. Intensive Care Med 2017;43(01):48-58

36 Martin-Loeches I, Lemiale V, Geoghegan P, et al; Efraim investigators and the Nine-I study group. Influenza and associated coinfections in critically ill immunosuppressed patients. Crit Care 2019;23(01):152

37 Martín-Loeches I, Sanchez-Corral A, Diaz E, et al; H1N1 SEMICYUC Working Group. Community-acquired respiratory coinfection in critically ill patients with pandemic 2009 influenza $A(H 1 N 1)$ virus. Chest 2011;139(03):555-562

38 Schauwvlieghe AFAD, Rijnders BJA, Philips N, et al; Dutch-Belgian Mycosis study group. Invasive aspergillosis in patients admitted to the intensive care unit with severe influenza: a retrospective cohort study. Lancet Respir Med 2018;6(10):782-792

39 Muthuri SG, Venkatesan S, Myles PR, et al; PRIDE Consortium Investigators. Impact of neuraminidase inhibitors on influenza $A$
(H1N1)pdm09-related pneumonia: an individual participant data meta-analysis. Influenza Other Respir Viruses 2016;10(03): 192-204

40 Rodríguez A, Díaz E, Martín-Loeches I, et al; H1N1 SEMICYUC Working Group. Impact of early oseltamivir treatment on outcome in critically ill patients with 2009 pandemic influenza A. J Antimicrob Chemother 2011;66(05):1140-1149

41 Lytras T, Mouratidou E, Andreopoulou A, Bonovas S, Tsiodras S. Effect of early oseltamivir treatment on mortality in critically ill patients with different types of influenza: a multi-season cohort study. Clin Infect Dis 2019 (e-pub ahead of print). Doi:10.1093/ $\mathrm{cid} / \mathrm{ciz} 101$

42 Ariano RE, Sitar DS, Zelenitsky SA, et al. Enteric absorption and pharmacokinetics of oseltamivir in critically ill patients with pandemic (H1N1) influenza. CMAJ 2010;182(04):357-363

43 Network SEAIDCR; South East Asia Infectious Disease Clinical Research Network. Effect of double dose oseltamivir on clinical and virological outcomes in children and adults admitted to hospital with severe influenza: double blind randomised controlled trial. BMJ 2013;346:f3039

44 World Health Organization. WHO Guidelines for Pharmacological Management of Pandemic Influenza A(H1N1) 2009 and Other Influenza Viruses. https://www.who.int/csr/resources/publications/swineflu/h1n1_guidelines_pharmaceutical_mngt_part2.pdf. Accesed 15 June 2019

45 Fiore AE, Fry A, Shay D, Gubareva L, Bresee JS, Uyeki TM; Centers for Disease Control and Prevention (CDC). Antiviral agents for the treatment and chemoprophylaxis of influenza - recommendations of the Advisory Committee on Immunization Practices (ACIP). MMWR Recomm Rep 2011;60(01):1-24

46 Yoo JW, Choi SH, Huh JW, Lim CM, Koh Y, Hong SB. Peramivir is as effective as oral oseltamivir in the treatment of severe seasonal influenza. J Med Virol 2015;87(10):1649-1655

47 Kong LK, Zhou BP. Successful treatment of avian influenza with convalescent plasma. Hong Kong Med J 2006;12(06):489

$48 \mathrm{Yu} \mathrm{H}$, Gao Z, Feng Z, et al. Clinical characteristics of 26 human cases of highly pathogenic avian influenza A (H5N1) virus infection in China. PLoS One 2008;3(08):e2985

49 Zhou B, Zhong N, Guan Y. Treatment with convalescent plasma for influenza A (H5N1) infection. N Engl J Med 2007;357(14): $1450-1451$

50 Hung IF, To KK, Lee CK, et al. Convalescent plasma treatment reduced mortality in patients with severe pandemic influenza $A$ (H1N1) 2009 virus infection. Clin Infect Dis 2011;52(04):447-456

51 Hui DS, Lee N, Chan PK, Beigel JH. The role of adjuvant immunomodulatory agents for treatment of severe influenza. Antiviral Res 2018;150:202-216

52 Martín-Loeches I, Bermejo-Martin JF, Vallés J, et al; SEMICYUC/ REIPI/CIBERES H1N1 Working Group. Macrolide-based regimens in absence of bacterial co-infection in critically ill $\mathrm{H} 1 \mathrm{~N} 1$ patients with primary viral pneumonia. Intensive Care Med 2013;39(04): 693-702

53 Lansbury L, Rodrigo C, Leonardi-Bee J, Nguyen-Van-Tam J, Lim WS Corticosteroids as adjunctive therapy in the treatment of influenza. Cochrane Database Syst Rev 2019;2:CD010406

54 Zhang Y, Sun W, Svendsen ER, et al. Do corticosteroids reduce the mortality of influenza A (H1N1) infection? A meta-analysis. Crit Care 2015;19:46

55 Yang JW, Fan LC, Miao XY, et al. Corticosteroids for the treatment of human infection with influenza virus: a systematic review and meta-analysis. Clin Microbiol Infect 2015;21(10):956-963

56 Rodrigo C, Leonardi-Bee J, Nguyen-Van-Tam JS, Lim WS. Effect of corticosteroid therapy on influenza-related mortality: a systematic review and meta-analysis. J Infect Dis 2015;212(02):183-194

57 Sukhal S, Sethi J, Ganesh M, Villablanca PA, Malhotra AK, Ramakrishna $\mathrm{H}$. Extracorporeal membrane oxygenation in severe influenza infection with respiratory failure: a systematic review and meta-analysis. Ann Card Anaesth 2017;20(01):14-21 
58 Estabragh ZR, Mamas MA. The cardiovascular manifestations of influenza: a systematic review. Int J Cardiol 2013;167(06):2397-2403

59 Onitsuka H, Imamura T, Miyamoto N, et al. Clinical manifestations of influenza a myocarditis during the influenza epidemic of winter 1998-1999. J Cardiol 2001;37(06):315-323

60 Sellers SA, Hagan RS, Hayden FG, Fischer WA II. The hidden burden of influenza: a review of the extra-pulmonary complications of influenza infection. Influenza Other Respir Viruses 2017;11(05):372-393

61 Brown SM, Pittman J, Miller lii RR, et al. Right and left heart failure in severe H1N1 influenza A infection. Eur Respir J 2011;37(01):112-118

62 Warren-Gash C, Bhaskaran K, Hayward A, et al. Circulating influenza virus, climatic factors, and acute myocardial infarction: a time series study in England and Wales and Hong Kong. J Infect Dis 2011;203(12):1710-1718

63 Kwok CS, Aslam S, Kontopantelis E, et al. Influenza, influenza-like symptoms and their association with cardiovascular risks: a systematic review and meta-analysis of observational studies. Int J Clin Pract 2015;69(09):928-937

64 Ciszewski A, Bilinska ZT, Brydak LB, et al. Influenza vaccination in secondary prevention from coronary ischaemic events in coronary artery disease: FLUCAD study. Eur Heart J 2008;29 (11):1350-1358

65 Siriwardena AN, Gwini SM, Coupland CA. Influenza vaccination, pneumococcal vaccination and risk of acute myocardial infarction: matched case-control study. CMAJ 2010;182(15):1617-1623

66 Corrales-Medina VF, Madjid M, Musher DM. Role of acute infection in triggering acute coronary syndromes. Lancet Infect Dis 2010;10(02):83-92

67 Meijer WJ, Linn FHH, Wensing AMJ, et al. Acute influenza virusassociated encephalitis and encephalopathy in adults: a challenging diagnosis. JMM Case Rep 2016;3(06):e005076

68 Tam CC, O’Brien SJ, Petersen I, Islam A, Hayward A, Rodrigues LC. Guillain-Barré syndrome and preceding infection with campylobacter, influenza and Epstein-Barr virus in the general practice research database. PLoS One 2007;2(04):e344

69 Stowe J, Andrews N, Wise L, Miller E. Investigation of the temporal association of Guillain-Barre syndrome with influenza vaccine and influenzalike illness using the United Kingdom General Practice Research Database. Am J Epidemiol 2009;169(03):382-388

70 Borgatta B, Pérez M, Rello J, et al; pH1N1 GTEI/SEMICYUC. Elevation of creatine kinase is associated with worse outcomes in 2009 pH1N1 influenza A infection. Intensive Care Med 2012;38 (07):1152-1161

71 Wong JY, Kelly H, Cheung CM, et al. Hospitalization fatality risk of influenza A(H1N1)pdm09: a systematic review and meta-analysis. Am J Epidemiol 2015;182(04):294-301

72 Khandaker G, Dierig A, Rashid H, King C, Heron L, Booy R. Systematic review of clinical and epidemiological features of the pandemic influenza A (H1N1) 2009. Influenza Other Respir Viruses 2011;5(03):148-156

73 Duggal A, Pinto R, Rubenfeld G, Fowler RA. Global variability in reported mortality for critical illness during the 2009-10 influenza A(H1N1) pandemic: a systematic review and meta-regression to guide reporting of outcomes during disease outbreaks. PLoS One 2016;11(05):e0155044

74 Hotchkiss RS, Monneret G, Payen D. Immunosuppression in sepsis: a novel understanding of the disorder and a new therapeutic approach. Lancet Infect Dis 2013;13(03):260-268

75 Bruynseels P, Jorens PG, Demey HE, et al. Herpes simplex virus in the respiratory tract of critical care patients: a prospective study. Lancet 2003;362(9395):1536-1541

76 Luyt CE, Combes A, Deback C, et al. Herpes simplex virus lung infection in patients undergoing prolonged mechanical ventilation. Am J Respir Crit Care Med 2007;175(09):935-942

77 Ong GM, Lowry K, Mahajan S, et al. Herpes simplex type 1 shedding is associated with reduced hospital survival in patients receiving assisted ventilation in a tertiary referral intensive care unit. J Med Virol 2004;72(01):121-125

78 Linssen CF, Jacobs JA, Stelma FF, et al. Herpes simplex virus load in bronchoalveolar lavage fluid is related to poor outcome in critically ill patients. Intensive Care Med 2008;34(12):2202-2209

79 Costa C, Sidoti F, Saldan A, et al. Clinical impact of HSV-1 detection in the lower respiratory tract from hospitalized adult patients. Clin Microbiol Infect 2012;18(08):E305-E307

80 De Vos N, Van Hoovels L, Vankeerberghen A, et al. Monitoring of herpes simplex virus in the lower respiratory tract of critically ill patients using real-time PCR: a prospective study. Clin Microbiol Infect 2009;15(04):358-363

81 Luyt CE, Combes A, Nieszkowska A, Trouillet JL, Chastre J. Viral infections in the ICU. Curr Opin Crit Care 2008;14(05):605-608

82 Coisel Y, Bousbia S, Forel JM, et al. Cytomegalovirus and herpes simplex virus effect on the prognosis of mechanically ventilated patients suspected to have ventilator-associated pneumonia. PLoS One 2012;7(12):e51340

83 Tuxen DV, Wilson JW, Cade JF. Prevention of lower respiratory herpes simplex virus infection with acyclovir in patients with the adult respiratory distress syndrome. Am Rev Respir Dis 1987;136 (02):402-405

84 Traen S, Bochanen N, leven M, et al. Is acyclovir effective among critically ill patients with herpes simplex in the respiratory tract? JClin Virol 2014;60(03):215-221

85 Jaber S, Chanques G, Borry J, et al. Cytomegalovirus infection in critically ill patients: associated factors and consequences. Chest 2005;127(01):233-241

86 Limaye AP, Kirby KA, Rubenfeld GD, et al. Cytomegalovirus reactivation in critically ill immunocompetent patients. JAMA 2008;300(04):413-422

87 Chiche L, Forel JM, Roch A, et al. Active cytomegalovirus infection is common in mechanically ventilated medical intensive care unit patients. Crit Care Med 2009;37(06):1850-1857

88 Limaye AP, Stapleton RD, Peng L, et al. Effect of ganciclovir on IL-6 levels among cytomegalovirus-seropositive adults with critical illness: a randomized clinical trial. JAMA 2017;318(08):731-740

89 Papazian L, Fraisse A, Garbe L, et al. Cytomegalovirus. An unexpected cause of ventilator-associated pneumonia. Anesthesiology 1996;84(02):280-287

90 Papazian L, Doddoli C, Chetaille B, et al. A contributive result of open-lung biopsy improves survival in acute respiratory distress syndrome patients. Crit Care Med 2007;35(03):755-762

91 Li X, Huang Y, Xu Z, et al. Cytomegalovirus infection and outcome in immunocompetent patients in the intensive care unit: a systematic review and meta-analysis. BMC Infect Dis 2018;18(01):289

92 Cowley NJ, Owen A, Shiels SC, et al. Safety and efficacy of antiviral therapy for prevention of cytomegalovirus reactivation in immunocompetent critically ill patients: a randomized clinical trial. JAMA Intern Med 2017;177(06):774-783

93 Tachikawa R, Tomii K, Seo R, et al. Detection of herpes viruses by multiplex and real-time polymerase chain reaction in bronchoalveolar lavage fluid of patients with acute lung injury or acute respiratory distress syndrome. Respiration 2014;87(04):279-286

94 Libert N, Bigaillon C, Chargari C, et al. Epstein-Barr virus reactivation in critically ill immunocompetent patients. Biomed J 2015; 38(01):70-76

95 Ong DSY, Bonten MJM, Spitoni C, et al; Molecular Diagnosis and Risk Stratification of Sepsis Consortium. Epidemiology of multiple herpes viremia in previously immunocompetent patients with septic shock. Clin Infect Dis 2017;64(09):1204-1210

96 Forel JM, Martin-Loeches I, Luyt CE. Treating HSV and CMV reactivations in critically ill patients who are not immunocompromised: pro. Intensive Care Med 2014;40(12):1945-1949

97 Papazian L, Hraiech S, Lehingue S, et al. Cytomegalovirus reactivation in ICU patients. Intensive Care Med 2016;42(01):28-37 